\title{
Análises dos currículos estaduais de Educação Física: inconsistências e incoerências percebidas
}

Marcos Garcia Neira

(Universidade de São Paulo, São Paulo, SP)
Resumo: Na tentativa de formar o sujeito que reconstruirá a sociedade, as redes estaduais elaboraram propostas curriculares com o intuito de orientar a ação pedagógica dos seus docentes. Em se tratando de um componente específico, a importância de tal iniciativa se faz acompanhar da necessidade de identificar as concepções que influenciam esses documentos e quais conhecimentos são considerados válidos. Com esse intuito, analisamos os currículos de Educação Física do Acre, Alagoas, Mato Grosso, Paraná, Pernambuco e São Paulo, mediante o confronto com a teorização curricular do componente. Os resultados indicam que alguns estados permanecem atrelados às tendências tradicionais do currículo, enquanto outros adotam um posicionamento crítico para o trabalho com as práticas corporais na escola. Inconsistências e incoerências teóricometodológicas ainda são percebidas na maioria dos casos.

Palavras-chave: Educação Física. Currículo. Cultura. 


\section{INTRODUÇÃO}

Este artigo sintetiza as análises das propostas curriculares de Educação Física para o segundo segmento do ensino fundamental, publicadas por seis estados da federação entre 2008 e 2014: Acre, Alagoas, Mato Grosso, Pernambuco, São Paulo e Paraná. O estudo compôs a segunda fase do macroprojeto "Currículos para os anos finais do ensino fundamental: concepções, modos de implantação, usos”, realizado pelo Centro de Estudos e Pesquisas em Educação, Cultura e Ação Comunitária (Cenpec), durante a qual os documentos específicos dos componentes curriculares foram objeto de investigação detalhada.

Tendo por objetivo principal "descrever e analisar as políticas curriculares para os anos finais do ensino fundamental dos estados brasileiros" (CENPEC, 2015, p. 14), a atual pesquisa debruçou-se sobre os currículos oficiais da Educação Física com o intuito de identificar as concepções que orientam os documentos e como são abordados os conteúdos do componente. Com base nesses objetivos comuns a todas as disciplinas, os especialistas convidados para essa fase elaboraram, juntamente com os coordenadores da pesquisa, um instrumento contendo nove itens (Conteúdos de ensino e aprendizagem; Fundamentos teóricos; Didatização e implementação; Articulação entre o universal e o local na disciplina; Abordagem da questão da diversidade na disciplina; Abordagem da avaliação e possíveis relações com avaliações externas; Relações entre os documentos de ensino fundamental 1, 2 e médio; Complementos e Síntese da análise da disciplina) e 28 subitens. 0 instrumento direcionou o olhar dos especialistas de maneira a permitir a análise de aspectos similares nos diversos documentos curriculares. No caso da Educação Física, as análises foram enriquecidas a partir do confronto do conteúdo presente nos documentos com a teorização curricular do componente.

\section{AS TEORIAS CURRICULARES DA EdUCAÇÃo FÍSICA}

No decorrer de sua trajetória, os objetivos e sentidos da Educação Física se modificaram de acordo com o contexto sócio-histórico e político. Suas transformações se alinharam aos interesses de cada época, seja como instrumento de implantação de ações higienistas, defesa de um pensamento desenvolvimentista, atendimento aos pressupostos neoliberais ou à busca de uma formação crítica. Desde o surgimento, suas intenções foram e são as mais diversas, caracterizando um campo bastante complexo em que 
posicionamentos há algum tempo questionados volta e meia ressuscitam para assombrar professores e alunos. Enquanto a maior parte dos documentos oficiais revela-se inclinada a uma concepção do componente inserido na área das linguagens, um conjunto não desprezível de forças ainda o impele aos pressupostos biologicistas.

A Educação Física sob a forma escolarizada surge na Europa em finais do século XVIII. Simultaneamente à estruturação dos sistemas nacionais de ensino, consolidava-se um novo modelo social subscrito ao capitalismo. Logo, a prática dos exercícios físicos cumpria dois papéis complementares: a formação dos sujeitos empreendedores que assumiriam os postos de liderança e a de cidadãos submissos que atuariam como mão de obra nas linhas de produção.

Naquele contexto, sobressaía a preocupação das autoridades estatais com o corpo, a saúde e a força de trabalho da população. Vistas como meio de desenvolvimento físico e moral, as atividades corporais sistematizadas cumpriam intenções e objetivos higienistas. O surgimento dos métodos ginásticos foi um episódio decisivo para a inclusão dessa prática nas instituições educativas, reforçando os vínculos entre a Educação Física e a aquisição e melhoria da saúde.

O currículo ginástico expandiu-se pelo mundo ocidental, inclusive para o continente americano. No caso brasileiro, a penetração nas escolas deuse por intermédio de instrutores ligados às forças armadas. Revestida pelo discurso nacionalista, a ginástica tornou-se obrigatória ao final dos anos 1930, período em que o pensamento escolanovista conferiu relevância à Educação Física com a valorização do jogo enquanto recurso didático fundamental para a educação integral. Todavia, o caráter progressista e contestatório com respeito à tradição educacional da época dificultou a disseminação nas escolas e a plena aceitação dos seus pressupostos.

Após a Segunda Guerra Mundial surgiram outras correntes que entraram na disputa pelo significado da Educação Física escolar, sobretudo o Método Desportivo Generalizado. Atendendo ao projeto político-econômico de transformação do país em uma nação urbana e industrial, o currículo esportivo ganhou força e conquistou importantes adeptos junto aos setores mais influentes: industriais, intelectuais e jornalistas.

Diante de um novo contexto e sob fortes impulsos da tecnologia, os objetivos educacionais se voltaram para a formação de sujeitos coerentes com as 
novas demandas do mundo do trabalho. Em termos pedagógicos, o período foi marcado pela influência do tecnicismo educacional. A racionalização dos meios em busca da eficiência se coadunava com os pressupostos esportivos. Visto como uma prática objetiva, regrada, com especialização de funções e por apresentar condições objetivas passíveis de mensuração e comparação, o currículo esportivo tornou-se ideal para a formação dos sujeitos requisitados por uma sociedade fabril (NEIRA; NUNES, 2009).

Reproduzindo em grande escala os mesmos exercícios seccionados que caracterizam o treinamento esportivo, as aulas do componente voltaramse para a fixação da gestualidade e a inculcação dos valores que forjariam o caráter empreendedor e competitivo necessários à sociedade industrial (LINHALES, 2009). Se do ponto de vista epistemológico os conhecimentos de viés biofisiológico tornaram-se os principais alicerces das ações didáticas do componente, olhando sob o prisma político, o contexto da época mostrou-se propício à propagação de uma pedagogia centrada no professor, que por sua vez não questionava os conteúdos a serem ensinados. Voltado para o controle social, o currículo esportivo confundiu-se novamente com a formação moral dos sujeitos, carregando toda uma simbologia de perseverança, superação e meritocracia.

A partir da década de 1980 o paradigma da aptidão física começou a sofrer abalos. Eclodiram contestações acerca dos objetivos, métodos e conteúdos da Educação Física e os fundamentos que sustentavam o componente enquanto experiência educacional foram revistos, levando pesquisadores a inspirar-se nas teorias do crescimento e desenvolvimento humanos para propor alternativas e superar a primazia do ensino esportivo na escola.

Sob influência do discurso educacional cognitivista e mediante as contribuições de pesquisadores franceses, surgiu o método psicocinético, também conhecido por psicomotricidade. 0 currículo psicomotor visa ao desenvolvimento pleno da criança, atentando aos aspectos motores, socioafetivos e cognitivos (FREIRE, 1989). Com a contribuição da psicomotricidade, os planos de ensino da Educação Física, ainda baseados no tecnicismo educacional, incorporam objetivos pertencentes aos três domínios do comportamento. Por meio de atividades motoras adequadamente planejadas, o trabalho pedagógico garantiria o refinamento das habilidades exigidas dentro e fora da escola. "Pelo movimento" seria possível prevenir e remediar as dificuldades de aprendizagem, assim como garantir a construção de estruturas psicológicas que formariam a base para um desenvolvimento normal. 
As teorias psicológicas e, principalmente, os resultados de pesquisas britânicas e estadunidenses sobre o crescimento e desenvolvimento humanos fizeram despontar a proposta curricular desenvolvimentista (TANI et al., 1988). Baseada na correspondência entre maturação biológica e níveis de desempenho cognitivos, socioafetivos e motores, a vertente dispunha uma programação adequada de atividades motoras como forma de estímulo aos demais domínios do comportamento. Além disso, responsabilizou a Educação Física pela aprendizagem do movimento, relacionando-a intrinsecamente ao desenvolvimento global. Segundo a perspectiva desenvolvimentista, caberia ao professor organizar situações didáticas que levassem os alunos a alcançar estágios maduros das habilidades motoras, a fim de que todos pudessem executar satisfatoriamente as atividades cotidianas.

Tirante o fato de ambas as concepções de ensino recorrerem à psicologia como campo epistemológico principal, em termos práticos as semelhanças são poucas. Enquanto na proposta psicomotora a realização de movimentos é o principal meio da atividade educativa, a vertente desenvolvimentista preocupa-se, sobretudo, com a qualidade da execução, tida como finalidade principal da Educação Física.

O contexto neoliberal dos anos 1990 propiciou as condições para o surgimento de outra perspectiva curricular para a Educação Física: a saúde renovada (GUEDES, 1999). Com o intuito de combater o sedentarismo e as mazelas relacionadas à diminuição da atividade física, consequências do mundo contemporâneo, essa vertente curricular tinha por objetivos o ensino de conceitos e procedimentos relacionados à prática de exercícios com vistas à adoção e manutenção de um estilo de vida fisicamente ativo. Apoiava-se no seguinte raciocínio: uma vez conhecedor dos princípios biomecânicos e fisiológicos, além dos meios necessários para melhorar a própria performance, o sujeito passaria a responsabilizar-se pela condução de uma vida saudável.

O que se percebe até aqui é que tais propostas se amparavam em uma visão descontextualizada, monocultural e excludente de educação, bem ao gosto da sociedade capitalista da época, mas absolutamente distante das atuais demandas sociais e, principalmente, pedagógicas da contemporaneidade. Trata-se de perspectivas tecnicistas da Educação Física fundamentadas nas teorias tradicionais do currículo (SILVA, 2011), pois não é seu propósito promover uma análise, tampouco a compreensão da ocorrência social das práticas corporais. Não possuem o menor compromisso com a superação dos problemas sociais que promovem a injustiça, a desigualdade e as condições de vida degradantes de uma grande parcela dos cidadãos. 
As últimas décadas do século XX também presenciaram o questionamento do papel que a escola exercia no sistema capitalista. Inúmeros trabalhos sinalizaram o viés reprodutivista (LOPES; MACEDO, 2011) da instituição e sua condição de agência a favor da perpetuação das condições sociais vigentes. Um país que enfrentava o processo de redemocratização teria, obrigatoriamente, de combater o elitismo reinante dentro dos muros escolares. Em termos teóricos, o materialismo dialético tornou-se a principal referência para explicar o fenômeno e, simultaneamente, oferecer alternativas de superação. Como não poderia deixar de ser, a Educação Física, enquanto prática social e experiência formativa, também sofreu as influências dos debates reformistas que se instauraram na sociedade brasileira.

O componente vivenciou uma mudança paradigmática ao adotar as ciências humanas como campo teórico. A transformação mais evidente foi a sua inserção na área das linguagens a partir do entendimento da gestualidade como forma de comunicação. Os movimentos, devidamente contextualizados, passaram a ser vistos como recursos que os grupos sociais empregam para veicular intenções e pensamentos. As teorias de cunho psicobiológico que até então fundamentavam as ações didáticas abriram temporariamente um espaço para a história, a sociologia, a antropologia, a filosofia, a política e a semiótica.

Referenciadas nas teorias críticas da educação, as perspectivas críticosuperadora (SOARES et al., 1992) e crítico-emancipatória (KUNZ, 1994) surgiram como propostas curriculares redentoras para o ensino da Educação Física. Ressaltaram aspectos importantes ao denunciar que as aulas do componente, principalmente aquelas baseadas no currículo esportivo, transmitiam e mantinham os valores da classe privilegiada e dos condicionantes capitalistas. Como alternativa, sugeriram novos procedimentos metodológicos, propondo ações dialógicas e reflexivas sobre o processo de construção das práticas corporais no intuito de conscientizar os alunos dos mecanismos de dominação presentes na sociedade e posicionando-os como autores do processo pedagógico.

A cultura corporal tornou-se o objeto de estudo da Educação Física, o que engloba todos os conhecimentos, discursos e representações sobre as manifestações da motricidade humana sistematizadas com características lúdicas, historicamente produzidas e reproduzidas pelos grupos sociais: brincadeiras, danças, lutas, esportes e ginástica. Contudo, há que se destacar o surgimento, com o decorrer do tempo, de concepções de cultura corporal que 
se diferenciam, pois cada perspectiva de ensino se fundamenta em campos epistemológicos distintos (NEIRA; GRAMORELLI, 2015).

Nos anos mais recentes, a preocupação com um ensino de Educação Física sensível às marcas da sociedade pós-moderna e à função que a escola adquiriu no presente momento fizeram surgir uma proposta curricular fundamentada nas teorias pós-críticas do currículo, especialmente os estudos culturais e o multiculturalismo crítico, o denominado currículo cultural (NEIRA, 2011). As teorias pós-críticas não negam as contribuições das teorias críticas para refletir a sociedade, a escola e a área, mas apresentam formas de explicar a realidade que se diferem, além do que, possuem preocupações distintas.

As teorias pós-críticas alertam que todas as práticas corporais, enquanto textos da cultura, são perpassadas por relações de poder que têm na classe, etnia, gênero, religião, idade, nível de habilidade etc. alguns dos seus marcadores sociais. As teorias pós-críticas colocam em xeque as metanarrativas, as noções de progresso, a autonomia, a emancipação e a libertação do sujeito alentadas pelas teorias críticas, por não concordarem com os princípios do universalismo, essencialismo e fundamentalismo que dão sustentação ao pensamento moderno (SILVA, 2011).

Os estudos culturais e o multiculturalismo crítico inspiram professores e alunos a analisar os signos do poder presentes nas brincadeiras, danças, lutas, esportes e ginástica, examinar as relações de dominação e subjugação envolvidas e, consequentemente, quais identidades são valorizadas e quais são menosprezadas pelos discursos e representações propositadamente conectados às práticas corporais. O currículo cultural da Educação Física busca procedimentos mais democráticos diante dos diversos grupos que coabitam a sociedade, promove todas as vozes, rompe com preconceitos e hierarquizações, valoriza os conhecimentos científicos, populares e do senso comum, incentiva posturas críticas e se opõe radicalmente à formação de sujeitos segundo os pressupostos neoliberais que fixam identidades e grupos. 


\section{ANÁLISE E DISCUSSÃO}

Acre

A organização do documento segue a distribuição tradicional: objetivos, conteúdos, propostas de atividades e formas de avaliação. Em um longo texto introdutório, o documento (ACRE, 2010) apresenta e fundamenta a tipologia dos conteúdos (procedimentais, atitudinais e conceituais), claramente inspirada em Zabala (1998). Na seção específica da Educação Física, alerta o professor que o esquecimento dos conteúdos conceituais e atitudinais pode causar a exclusão dos alunos (ACRE, 2010, p. 21). Constata-se, no entanto, uma visão distorcida do que seriam os conteúdos conceituais e atitudinais na área e como proporcionar a sua aprendizagem.

O texto, porém, mostra certa confusão teórica quando defende a importância do acesso dos jovens à cultura corporal, explicitando que "representa uma oportunidade de diálogo com o ambiente cultural, com tradições, sentidos e significados que as diferentes práticas transformam e ressignificam a cada tempo e contexto" (ACRE, 2010, p. 21).

O que se constata é a colisão de duas propostas para a seleção dos conteúdos: a tipologia herdada da tradição acadêmica e consolidada pelos Parâmetros Curriculares Nacionais - PCN (BRASIL, 1998) e a preocupação com as demandas sociais referenciadas no viés dialógico. Ao longo do texto é impossível identificar uma referência teórica específica. A seção destinada ao assunto tergiversa sobre o jovem de maneira bastante ampla e superficial, sem fundamentar a visão de disciplina. Seguindo o mesmo raciocínio presente nos PCN, elege objetos de ensino incongruentes (uma visão apolítica da cultura corporal e dos conhecimentos sobre o corpo visando à adoção de um estilo de vida fisicamente ativo).

Dentre as peculiaridades do documento, vale a pena destacar a menção a uma atividade de ensino e de uma proposta de avaliação para cada um dos conteúdos mencionados. Obviamente, muitas propostas são repetidas inúmeras vezes.

\section{Alagoas}

O documento alagoano (ALAGOAS, 2010) apresenta alguns princípios norteadores para a organização curricular. São amplos, valorizam a experiência dos alunos e dos professores e compreendem a escola como lócus de aprendizagens, entre outras características. Todavia, contrariando essa 
prometida abertura, os conteúdos da Educação Física foram selecionados a partir da tradição da disciplina, pautando-se no aprimoramento das habilidades motoras e visando à melhoria do desempenho corporal.

Vivenciar nas diversas modalidades esportivas movimentos corporais específicos de: o drible, a recepção, o passe, o arremesso, o chute, o lance etc.; Reconhecer a variabilidade de tipos, nomes, regras, espaços físicos e formas de jogar o a mesma modalidade; Conhecer as formas de execução de exercícios em aparelhos fixos e manuais: o plinto, barra, cavalo, corda, bola, arco etc.; Conhecer e executar os fundamentos de diversas modalidades esportivas: voleibol, futebol, basquete, handebol etc. e Conhecer, valorizar, respeitar e desfrutar da pluralidade das manifestações do esporte, como recurso valioso para a integração entre pessoas e diferentes grupos sociais (ALAGOAS, 2010, p. 77).

É perceptível que grande parte dos conteúdos arrolados se refere ao currículo esportivo. Uma quantidade menor recupera uma visão higienista do componente, voltada para a adoção de um estilo de vida fisicamente ativo. Tome-se o seguinte exemplo: "Demonstrar habilidades de reação, resistência aeróbica e coordenação motora em diversas atividades físicas e corporais" e "Reconhecer os efeitos da atividade física sobre o organismo e a saúde" (ALAGOAS, 2010, p. 77).

Muito embora seja visível o apoio nos fundamentos biofisiológicos, a concepção da Educação Física não é explicitada no documento. A fixação da gestualidade esportiva e o desenvolvimento das capacidades físicas evidenciam a concepção tradicional do currículo. A quantidade restrita de conteúdos e a não explicitação da abordagem metodológica ou das obras que subsidiam o ensino da disciplina criam obstáculos à compreensão do professor, que muito provavelmente recorrerá a outras fontes para planejar e desenvolver suas ações didáticas. A carência de explicações que ajudem o docente a atuar a partir dos fundamentos do documento pode abrir a possibilidade de uma prática pedagógica distanciada da proposta.

No que tange à abordagem teórico-metodológica, a proposta explicita apenas seu enfoque interdisciplinar. Para defendê-lo, explica que a interdisciplinaridade

\footnotetext{
[...] é uma abordagem teórico-metodológica que permite maior articulação e reflexão entre as diversas disciplinas ou entre a heterogeneidade de uma mesma ciência, garantindo uma análise mais dinâmica da realidade. A prática educativa da interdisciplinaridade não anula a contribuição de cada ciência em particular, mas é uma prática que possibilita a valoração de todo o conhecimento historicamente construído. Sua lógica é a da descoberta, havendo uma reciprocidade, uma comunicação entre as áreas de domínio do conhecimento, uma fecundação mútua entre os saberes disciplinares (ALAGOAS, 2010, p. 64).
} 
Mato Grosso

No documento curricular mato-grossense (MATO GROSSO, 2010a), a Educação Física se encontra na área de Linguagens e as práticas corporais são compreendidas como textos da cultura corporal. Os conteúdos, de forma coerente, são conceitos que possibilitem a compreensão da ocorrência social das manifestações da gestualidade e procedimentos que permitem a produção e reprodução destas. 0 posicionamento, nesse sentido, é claro:

Não cabe mais pensar o esporte como único conteúdo da Educação Física. Priorizar este ou aquele conteúdo supõe o parcelamento dessa cultura corporal, a negação de importantes conhecimentos construídos historicamente no contexto sociocultural relacionados às outras práticas corporais (MATO GROSSO, 2010a, p. 40).

E no $3^{\circ}$ Ciclo o estudante deverá ampliar conceitualmente os conhecimentos vinculados à cultura corporal de movimento (dança, jogos, lutas, ginástica, conhecimentos sobre o corpo e esportes, entre outros), a partir da consciência dos movimentos pertinentes a essas práticas, tendo condições de reinventá-las. $O$ estudante, no $3^{\circ} \mathrm{Ciclo}$, tem condições de reproduzir os movimentos técnicos relacionados ao esporte institucionalizado. $A$ exemplo da aprendizagem do saque no voleibol, não é suficiente vivenciar o gesto, é necessário conhecer a função dele no jogo, experimentar diferentes formas de execução e propiciar situações para que cada estudante encontre uma forma adequada de executá-lo, mesmo que tecnicamente seja considerado incorreto (MATO GROSSO, 2010a, p. 41).

\section{Embora os conteúdos da disciplina inovem ao mostrar coerência com a inserção na área de Linguagens, deixam a desejar com relação a outras propostas que aprofundam a análise das práticas corporais enquanto textos produzidos por meio de lutas por significação. Tal contradição pode ser constatada quando se confrontam os sentidos expressos em dois fragmentos:}

A aula de Educação Física é um espaço pedagógico privilegiado de produção de cultura em que os sentimentos, a criatividade, o lúdico e a corporeidade devem ser considerados.

A percepção dessas práticas corporais, como patrimônio cultural de um povo, deve proporcionar condições de compreender, reconhecer e respeitar essas práticas. $O$ trabalho do professor deve ser intencionalmente planejado para considerar as necessidades da criança na infância ligada pela perspectiva da Cultura (MATO GROSSO, 2010a, p. 20)

Assim, as aulas de Educação Física no $2^{\circ}$ Ciclo devem promover momentos de problematização e reflexão que permitam uma sistematização mais elaborada acerca dos elementos da cultura corporal de movimento (jogos, dança, ginástica, lutas, esporte e conhecimento sobre o corpo, entre outros) (MATO GROSSO, 2010a, p. 30). 
O documento explicita uma concepção metodológico-dialética:

Desse movimento decorre uma concepção metodológica que pode ser sistematizada da seguinte forma: o ponto de partida é sincrético, nebuloso, pouco elaborado, senso comum; o ponto de chegada é uma totalidade concreta, onde o pensamento recapta e compreende o conteúdo inicialmente separado e isolado do todo; sempre síntese provisória, essa totalidade parcial será novo ponto de partida para outros conhecimentos; os significados vão sendo construídos através do deslocamento incessante do pensamento das primeiras e precárias abstrações que constituem o senso comum, para o conhecimento elaborado através da práxis, que resulta não só da articulação entre teoria e prática, e entre sujeito e objeto, mas também entre o indivíduo e a sociedade em um dado momento histórico (MATO GROSSO, 2010b, p. 29-30).

Os materiais analisados permitem afirmar que o currículo de Educação Física de Mato Grosso se insere no conjunto de propostas alinhadas ao movimento mais recente da área. Apesar de breve, a fundamentação teórica apresentada é coerente e dá sustentação à proposta.

Paraná

No currículo paranaense (PARANÁ, 2008), os conhecimentos a ser ensinados foram definidos a partir dos chamados "Conteúdos Estruturantes" (esportes, jogos e brincadeiras, ginástica, lutas e danças). Embora o documento faça alusão a elementos articuladores desses conhecimentos (Cultura Corporal e Corpo; Cultura Corporal e Ludicidade; Cultura Corporal e Saúde; Cultura Corporal e Mundo do Trabalho; Cultura Corporal e Desportivização; Cultura Corporal - Técnica e Tática; Cultura Corporal e Lazer; Cultura Corporal e Diversidade; e Cultura Corporal e Mídia), não há qualquer explicação de como isso pode ser feito.

Os elementos articuladores alargam a compreensão das práticas corporais, indicam múltiplas possibilidades de intervenção pedagógica em situações que surgem no cotidiano escolar. São, ao mesmo tempo, fins e meios do processo de ensino/ aprendizagem, pois devem transitar pelos Conteúdos Estruturantes e específicos de modo a articulá-los o tempo todo (PARANÁ, 2008, p. 54).

Em termos conceituais, o documento se alinha à teoria curricular crítica da Educação Física:

[...] partindo de seu objeto de estudo e de ensino, cultura corporal, a Educação Física se insere neste projeto ao garantir o acesso ao conhecimento e à reflexão crítica das inúmeras manifestações ou práticas corporais historicamente produzidas pela humanidade, na busca de contribuir com um ideal mais amplo de formação de um ser humano crítico e reflexivo, reconhecendo-se como sujeito, que é produto, mas também agente histórico, político, social e cultural (PARANÁ, 2008, p. 42). 
De forma coerente com esse pressuposto, o currículo paranaense elucida a metodologia dialética adotada:

Ao pensar o encaminhamento metodológico para as aulas de Educação Física na Educação Básica, é preciso levar em conta, inicialmente, aquilo que o aluno traz como referência acerca do conteúdo proposto, ou seja, é uma primeira leitura da realidade. Esse momento caracteriza-se como preparação e mobilização do aluno para a construção do conhecimento escolar. Após o breve mapeamento daquilo que os alunos conhecem sobre o tema, o professor propõe um desafio remetendo-o ao cotidiano, criando um ambiente de dúvidas sobre os conhecimentos prévios. Por exemplo, levantar a seguinte questão sobre o jogo: todo jogo é necessariamente competitivo? Será que existe alguma maneira de jogar sem que exista um vencedor no final? Posteriormente, o professor apresentará aos alunos o conteúdo sistematizado, para que tenham condições de assimilação e recriação do mesmo, desenvolvendo, assim, as atividades relativas à apreensão do conhecimento através da prática corporal. Ainda neste momento, o professor realiza as intervenções pedagógicas necessárias, para que o jogo não se encaminhe desvinculado dos objetivos estabelecidos. Finalizando a aula, ou um conjunto de aulas, o professor pode solicitar aos alunos que criem outras variações de jogo, vivenciando-as. Neste momento, é possivel também a efetivação de um diálogo que permite ao aluno avaliar o processo de ensino/ aprendizagem, transformando-se intelectual e qualitativamente em relação à prática realizada (PARANÁ, 2008, p. 73).

Apesar da explicitação dos fundamentos teórico-metodológicos, o texto analisado não incorpora a problematização da cultura corporal e a ampliação do que vêm a ser os conteúdos de ensino da Educação Física defendidos pela perspectiva curricular crítica. Outro aspecto que chama a atenção e que diverge da vertente adotada é o fato de que as questões que atualmente influenciam a definição dos conteúdos, tais como marcadores sociais, preconceitos, inclusão etc., encontram-se ausentes.

Pernambuco

O objeto de ensino do currículo pernambucano (PERNAMBUCO, 2013) é a cultura corporal, compreendida como "o acervo de formas e representações do mundo que o ser humano tem produzido, exteriorizadas pela expressão corporal em jogo, dança, luta, ginástica e esporte” (PERNAMBUCO, 2013, p. 16).

Na proposta oficial, as práticas corporais são vistas como forma de trabalho não material consumido no mesmo instante em que é elaborado, possuindo finalidades lúdicas, competitivas e expressivas. Distribuídos em eixos, os "conteúdos" podem ser abstraídos a partir da leitura de algumas expectativas de aprendizagem, por exemplo, “Identificar as danças populares e folguedos, 
entre outras experiências rítmicas dos ciclos festivos de Pernambuco". Entretanto, na maioria das expectativas de aprendizagem, há alguma dificuldade na abstração dos conteúdos, como é o caso de "Investigar a ginástica, estabelecendo diferenças e semelhanças, formando conceitos, concepções, identificando regularidades subjacentes ao objeto de estudo".

Reproduzindo os pressupostos da proposta crítico-superadora (SOARES et al., 1992), infere-se da leitura do currículo pernambucano que o acesso ao conhecimento científico permitirá a substituição de uma noção sincrética da cultura corporal por uma visão crítica.

Ao relacionar expectativas de aprendizagem por eixo (jogo, dança, esporte, ginástica e luta) e não definir conteúdos a serem ensinados, o documento pernambucano reproduz o modelo das Orientações Curriculares do Município de São Paulo publicadas em 2007. Caso consideremos que o primeiro foi publicado em 2013, é fácil perceber que não se trata de uma inovação, sobretudo pelo fato de que a concepção de Educação Física que lhe dá sustentação remonta ao início dos anos 1990.

Em termos metodológicos, o texto curricular sugere como formas de organização das situações didáticas a aula, a oficina, o festival e o seminário, com base na pedagogia histórico-crítica (prática social inicial do conteúdo; problematização; instrumentalização; catarse; prática social final do conteúdo). Define cada um deles e afirma que se constituem em maneiras de satisfazer a necessidade de ação e curiosidade, aprofundando nexos e relações entre práticas corporais ou numa mesma prática, qualificando o rendimento escolar dos estudantes.

Observa-se, portanto, a continuidade da concepção que, desde 1990, inspira o ensino da Educação Física em Pernambuco. À época, rompendo com a tradição biologicista do componente, a proposta curricular adotou o materialismo histórico como base conceitual para a compreensão do objeto de ensino (cultura corporal) e a prática pedagógica (metodologia dialética). Muito embora os tempos sejam outros e o acúmulo de conhecimentos no campo sinalize outras possibilidades, no contexto local essa referência teórico-metodológica é importante e não pode ser desprezada.

É interessante notar que as questões que afetam a sociedade mais ampla e as realidades escolares em específico não mereceram atenção da proposta pernambucana, pois o foco do processo está na emancipação social das camadas populares (mencionadas no texto como proletariado) por meio do 
acesso ao que denominam conhecimento sistematizado, ou seja, os saberes científicos a respeito da cultura corporal. o currículo pernambucano aposta nesse caminho para a formação de sujeitos críticos, para que possam transformar a sociedade. 0 tratamento destinado às pessoas com deficiência e aos jovens e adultos impedidos de frequentar as aulas no período considerado “normal” ilustram bem a concepção homogeneizadora do documento.

São Paulo

No currículo paulista (SÃO PAULO, 2012), os conteúdos estão organizados em temas bimestrais. Tendo por objetivo evidenciar os significados/sentidos e intencionalidades presentes em jogo, esporte, ginástica, luta, atividade rítmica e organismo humano, movimento e saúde (SÃO PAULO, 2012, p. 226), o texto propõe a interface com os significados/sentidos e intencionalidades presentes nas codificações das culturas esportiva, lúdica, gímnica, das lutas e rítmica. Um exemplo do resultado desse cruzamento encontra-se na p. 244: “1ํㅡㄹ Bimestre do 9ํano: Tema 1 - Luta Modalidade: capoeira. Conteúdos: Capoeira como luta, jogo e esporte; Princípios técnicos e táticos e Processo histórico". Em síntese, o documento recupera os conteúdos convencionais da área, com o acréscimo dos conhecimentos pertencentes ao tema "Organismo humano, movimento e saúde” dos outros temas, reforçando o viés biológico.

Os objetivos do componente não se coadunam com os conteúdos propostos. A análise das habilidades previstas para cada bimestre (disponíveis nos cadernos do professor e do aluno ${ }^{1}$ ) aponta para a preocupação com a identificação de componentes e aspectos da prática corporal, sem qualquer atenção aos significados que lhe são atribuídos pelos grupos que as produzem e reproduzem. 0 alcance dos objetivos propostos requisitaria atividades de investigação, análise e compilação dos significados atribuídos às práticas corporais. Tais situações didáticas não são mencionadas nos materiais de apoio que acompanham o currículo. Reforçando a ausência dessa preocupação, os conteúdos são apresentados de forma universal, desconsiderando a enorme diversidade cultural do estado de São Paulo.

O texto disponibiliza uma série de quadros na tentativa de agrupar os conteúdos em temas, sem qualquer explicação dos critérios utilizados. Tampouco há justificativa sobre a seleção das modalidades esportivas a ser trabalhadas. Por exemplo, futebol e handebol surgem no $2^{\circ}$ bimestre do $6^{\circ}$ ano (SÃO PAULO,

Segundo informações contidas na apresentação dos cadernos do professor, o documento "apresenta orientações didático-pedagógicas e traz como base o conteúdo do Currículo Oficial do Estado de São Paulo, que pode ser utilizado como complemento à Matriz Curricular" [s.n.]. 
2012, p. 233) e ginástica artística e ginástica rítmica no 3ํㅡㅁ bimestre (SÃO PAULO, 2012, p. 234). A questão da complexidade dos conteúdos tampouco é levada em consideração. No tocante ao tema "Organismo humano, movimento e saúde”, por exemplo, no $2^{0}$ bimestre do mesmo ano solicita-se o ensino de "noções gerais das capacidades físicas" resistência, força e "postura" (que não é uma capacidade física) e, no 3 ํㅡ bimestre, é sugerido o conteúdo "aparelho locomotor".

O que a proposta estadual paulista de Educação Física procura fazer, e isso é evidente nos cadernos do aluno e do professor que apoiam a sua implantação, é fixar um único significado para os conteúdos ensinados. Vejase, por exemplo, o caso da tabela presente nas páginas 20 e 21 do volume 2 do Caderno do Professor do 9ำ ano. 0 formato, nome e regras de jogos como queimada, peteca, vinte e um, torrebol etc. já estão definidos, mesmo que a imensa maioria dos professores saiba que em qualquer escola a negociação das regras desses jogos ocorre todos os dias. A fixação dos significados é ainda mais contundente no tema "Organismo humano, movimento e saúde", quando o único estilo de vida aceito é o baseado na prática sistemática da atividade física, acompanhada de uma alimentação “saudável”, retomando alguns dos princípios básicos da educação para a saúde (GUEDES, 1999), apesar de a fundamentação apoiar-se na perspectiva crítico-emancipatória (KUNZ, 1994).

O caráter exaustivo das descrições que compõem os cadernos do professore do aluno permite atribuir ao material uma conotação prescritiva, principalmente porque o material do aluno contém exercícios correspondentes às situações de aprendizagem previstas no caderno do professor.

A concepção que inspira o documento se afasta dos debates contemporâneos da Educação Física. Não há menção às questões que afligem a sociedade atual e à característica multicultural da população escolar. Também surpreende a concepção instrumental que norteia o caderno do professor, que contém textos superficiais, tendenciosos e atividades fechadas, com pouca possibilidade de modificação pelos professores. 


\section{CONSIDERAÇÕES}

A análise dos documentos curriculares estaduais de Educação Física permitiu identificar a influência dos PCN na definição dos conteúdos a serem ensinados apenas no caso do Acre, cuja redação tentou abarcar conceitos, atitudes e procedimentos. Mesmo assim, apresenta alguma confusão ao estabelecer como princípio o diálogo com a cultura local. Em dois casos (Alagoas e Mato Grosso) foram privilegiados conceitos e procedimentos sem conexão com os PCN. O documento paranaense denomina como "conteúdos" as práticas corporais e as expectativas de aprendizagem. Já no currículo pernambucano, os conteúdos podem ser abstraídos do rol de expectativas de aprendizagem elencadas. Na proposta paulista, os conteúdos foram recortados dos temas da cultura corporal. 0 documento atribui o mesmo sentido às habilidades que, por sua vez, aludem exclusivamente a conhecimentos de ordem conceitual.

A seleção de conteúdos sofre influências da tradição da disciplina nas propostas do Acre, Alagoas e Paraná, enquanto em outras alinha-se ao movimento atual, inserindo a Educação Física na área das Linguagens e abordando os conteúdos como conhecimentos que permitirão ler e produzir as práticas culturais corporais - como exemplos destacam-se os currículos de Mato Grosso e Pernambuco.

A proposta paulista hibridiza as duas concepções ao propor conteúdos tradicionais, mas apresentar a disciplina como componente da área das Linguagens. Além disso, os temas (jogos, atividades rítmicas etc.) são definidos e distribuídos semestralmente. Não são mencionados critérios para essa distribuição, tampouco para os conteúdos e habilidades selecionados.

Os conteúdos propostos pelos currículos do Acre, Alagoas, Mato Grosso, Paraná e São Paulo são tratados como conhecimentos universais, sem qualquer alusão às especificidades locais. No documento oficial de Pernambuco, a preocupação com a cultura local é percebida ao chamar a atenção às danças populares e ciclos festivos do estado.

As propostas de Acre e Alagoas não assumem uma determinada concepção de Educação Física. Discorrem de forma ampla e superficial, sem apresentar fundamentos que sustentem a ação didática. Já os currículos de Mato Grosso, Paraná, Pernambuco e São Paulo explicitam a fundamentação na perspectiva cultural da Educação Física, apesar de fincarem seus alicerces em terrenos epistemológicos distintos: teorias pós-críticas, no caso de Mato Grosso, críticas (Paraná e Pernambuco) e tradicionais (São Paulo). Adotam a cultura corporal como objeto de estudo da área, mesmo que, nem sempre, as 
orientações didáticas se coadunem com as referências anunciadas.

Os debates contemporâneos da disciplina, sobretudo as questões que abrangem as diferenças culturais corporais, são mencionados, mesmo que de forma fragmentada, apenas no currículo acreano, enquanto as demais propostas não se mostram preocupadas com os marcadores sociais presentes nas práticas corporais ao longo do seu percurso histórico.

Entre as propostas analisadas, as do Acre e Paraná exemplificam ou fazem sugestões para o desenvolvimento de ações didáticas voltadas para o ensino dos conteúdos arrolados, apesar de não explicitarem uma linha metodológica para o trabalho pedagógico. Por sua vez, o documento alagoano não oferece exemplos, orientações didáticas nem propõe uma determinada metodologia de ensino. Os currículos de Mato Grosso, Paraná e Pernambuco não apresentam exemplos nem fazem sugestões, mas adotam explicitamente uma linha de concepção dialética. Por sua vez, a proposta paulista disponibiliza cadernos didáticos com indicações exaustivas e sequenciadas de atividades de ensino, sem explicitar uma concepção metodológica. A exceção é o trabalho com os esportes baseado em situações-problema.

A proposta alagoana dá relevo às questões étnico-raciais, de classe e gênero, além de alertar sobre a necessidade de promover mudanças curriculares no sentido de contemplar a diversidade e combater discriminações. 0 currículo mato-grossense menciona os marcadores de gênero, etnia e deficiências.

Ao abordar os eixos estruturantes, o currículo paranaense assinala a importância do trabalho com as danças afro-brasileiras e indígenas. Nas expectativas de aprendizagem, faz alusão aos jogos e lutas desses mesmos grupos étnicos. 0 documento pernambucano reserva um capítulo à discussão da inclusão de pessoas com deficiência sem sugerir quais procedimentos devem ser adotados. Defende que a perspectiva teórico-metodológica que perpassa o currículo é, por si só, inclusiva. No currículo estadual paulista, a única menção aos marcadores sociais reside nos conteúdos previstos para 0 $1^{0}$ bimestre do $7^{0}$ ano, ocasião em que a questão de gênero é abordada como relevante no trabalho com as atividades rítmicas.

A avaliação formativa e processual é a principal referência das propostas curriculares do Acre, Alagoas, Mato Grosso e Paraná. Nos documentos do Acre e do Paraná há sugestões para o emprego de instrumentos como observação, registro e análise, conforme o conteúdo abordado. No currículo estadual pernambucano, a avaliação é tratada como um meio para verificar o quanto o aluno se aproximou dos objetivos traçados e reorganizar o processo de ensino. 
0 texto sugere o emprego de instrumentos avaliativos como observação e prova escrita.

O documento paulista não explicita uma concepção de avaliação. 0 material didático que acompanha a proposta (caderno do professor) atrela os instrumentos de avaliação às habilidades que o currículo pretende desenvolver. Sugere questões a serem apresentadas aos alunos e aspectos a serem observados.

A análise dos documentos estaduais permite identificar ao menos três influências presentes na sua construção. A perspectiva curricular tradicional parece ter influenciado fortemente o currículo do Acre, de Alagoas e de São Paulo, enquanto nos demais se nota a preocupação de incorporar as experiências dos alunos.

As concepções de Educação Física também divergem. Mesmo que a expressão cultura corporal ou cultura de movimento sejam frequentes, os textos abrem mão de sua gênese crítica e, exceção feita às propostas de Mato Grosso e Pernambuco, resvalam ao sugerirem orientações didáticas que se coadunam com as tendências tradicionais do componente. O mesmo pode ser dito com relação à inserção da Educação Física na área das Linguagens. Alguns documentos afirmam fazê-lo, mas não posicionam as práticas corporais como artefatos da cultura, o que dificulta seu tratamento como textos a serem lidos, interpretados e produzidos durante as aulas. Preocupações com o ensino de movimentos padronizados ou fixação de noções como atividade física e saúde vão na contramão dessa intenção.

Essas contradições são reveladoras do próprio estado da arte em que se encontra o ensino da Educação Física. Circulam várias correntes e pressupostos que, não raro, confundem professores e elaboradores de currículos. Mas nada disso justifica as ausências e lacunas constatadas. Apesar do consenso existente na área a respeito do entendimento de cultura corporal como produção distintiva dos grupos que coabitam a sociedade, os documentos analisados privilegiam a tradição euro-americana, em detrimento das brincadeiras, danças, lutas, ginástica e esportes (ou dos significados a eles atribuídos) disseminados pelos grupos minoritários. O que dizer então da falta de menção à avaliação ou de orientações didáticas em algumas propostas? A ideia transmitida é que isso ficará a cargo do professor, o que provavelmente redundará na repetição de procedimentos cristalizados. Assim sendo, algumas boas propostas correm o risco de serem tergiversadas justamente pela não explicitação das ações pedagógicas que thes seriam mais adequadas. 


\section{An Analysis of Physical Education State Curricula: Inconsistencies and Incoherencies Found}

Abstract: In an attempt to educate the individuals that will rebuild society, the Brazilian state educational systems have designed curriculum proposals to guide the educational activities of their teachers. For each discipline, the importance of such proposals is accompanied by the need to identify the concepts that influence these documents and the knowledge that is considered valid. To that end, we analyze the curricula of physical education in the states of Acre, Alagoas, Mato Grosso, Paraná, Pernambuco and Sao Paulo by examining the curricular theorization for this particular discipline. Results indicate that some of these states remain tied to traditional curriculum trends, while others adopt a critical position to work with bodily practices at school. Theoretical and methodological inconsistencies and incoherencies can still be found in most cases.

Keywords: Physical education, curriculum, culture. 


\section{Análisis de los currículos estatales de Educación Física: inconsistencias e incoherencias percibidas}

Resumen: En el intento de formar al sujeto que reconstruirá la sociedad, las redes estatales elaboraron propuestas curriculares con el fin de orientar la acción pedagógica de sus docentes. Al tratarse de un componente específico, la importancia de tal iniciativa se ve acompañada de la necesidad de identificar las concepciones que influyen en estos documentos y los conocimientos que se consideran válidos. Con este objetivo, analizamos los currículos de Educación Física de Acre, Alagoas, Mato Grosso, Paraná, Pernambuco y São Paulo, mediante la confrontación con la teorización curricular del componente. Los resultados indican que algunos estados permanecen sujetos a las tendencias tradicionales del currículo, mientras que otros adoptan un posicionamiento crítico en el trabajo con las prácticas corporales en la escuela. En la mayoría de los casos, aún se perciben inconsistencias e incoherencias teóricometodológicas.

Palabras clave: Educación Física. Currículo. Cultura. 


\section{REFERÊNCIAS}

ACRE. Orientações Curriculares para o Ensino Fundamental. Caderno 1 Educação Física. Rio Branco: SEE, 2010.

ALAGOAS. Referencial Curricular da Educação Básica para as escolas públicas de Alagoas. Maceió: SEE, 2010.

BRASIL. Ministério da Educação e Desporto. Secretaria da Educação Fundamental. Parâmetros Curriculares Nacionais Terceiro e Quarto Ciclos do Ensino Fundamental: Educação Física. Brasília: MEC/SEF, 1998.

CENPEC. Currículos para os anos finais do ensino fundamental: concepções, modos de implantação, usos. Relatório de Pesquisa. São Paulo: Cenpec, 2015. Disponível em: 〈http://ftp.cenpec.org.br/com/portalcenpec/biblioteca/Relatorio_ Pesquisa_Curriculos_EF2_Final.pdf〉. Acesso em: 12 ago. 2015.

FREIRE, J. B. Educação de corpo inteiro. São Paulo: Scipione, 1989.

GUEDES, D. P. Educação para a saúde mediante programas de Educação Física escolar. Revista Motriz, Rio Claro, v. 5, n. 1, p. 10-14, jun. 1999.

KUNZ, E. Transformação didático-pedagógica do esporte. ljuí, RS: Ed. Unijuí, 1994.

LINHALES, M. Esporte e escola: astúcias na "energização do caráter" dos brasileiros. In: PRIORE, M. D.; MELO, V. A. História do esporte no Brasil: do Império aos dias atuais. São Paulo: Editora Unesp, 2009. p. 331-359.

LOPES, A C; MACEDO, E M. Teorias de currículo. São Paulo: Cortez, 2011.

MATO GROSSO. Orientações curriculares - Área de Linguagens, Educação Básica. Cuiabá: Seduc, 2010a.

Orientações curriculares: concepções para a Educação Básica. Cuiabá: Seduc, 2010b.

NEIRA, M. G. A reflexão e a prática do ensino: Educação Física. São Paulo: Blucher, 2011.

; GRAMORELLI, L. C. Embates em torno do conceito de cultura corporal: gênese e transformações. In: CONGRESSO BRASILEIRO DE CIÊNCIAS DO ESPORTE, 19, 2015, Vitória. Anais... Vitória, Ufes, 2015. 
; NUNES, M. L. F. Educação física, currículo e cultura. São Paulo: Phorte, 2009.

PARANÁ. Diretrizes Curriculares da Educação Básica - Educação Física. Curitiba: SEE, 2008.

PERNAMBUCO. Parâmetros para a Educação Básica do Estado de Pernambuco - Parâmetros Curriculares de Educação Física - Ensino Fundamental e Médio. Recife: SEE-PE, 2013.

SÃO PAULO. Currículo do Estado de São Paulo - Linguagens, códigos e suas tecnologias - Ensino Fundamental II e Ensino Médio. São Paulo: SEE/SP, 2012.

SILVA, T. T. Documentos de identidade: uma introdução às teorias do currículo. Belo Horizonte: Autêntica, 2011.

SOARES, C. L. et al. Metodologia do ensino da educação física. São Paulo: Cortez, 1992.

TANI, G. et al. Educação física escolar: fundamentos de uma abordagem desenvolvimentista. São Paulo: EPU/Edusp, 1988.

ZABALA, A. A prática educativa. Porto Alegre: Artmed, 1998.

Sobre os autores:

Marcos Garcia Neira, Livre-Docente em Metodologia do Ensino de Educação Física, Professor Titular da Faculdade de Educação da Universidade de São Paulo.

mgneira@usp.br

Recebido em: outubro de 2015

Aprovado em: janeiro de 2015 